\title{
Transolecranon fracture-dislocations of the elbow: a case series of 15 patients
}

\author{
Meryem Lemsanni*, Youssef Najeb, Rachid Chafik, Mohamed Madhar, Hanane El Haoury
}

Department of Orthopaedic and Trauma Surgery, Ibn Tofail Hospital, Mohammed VI University Hospital Center, Marrakesh, Morocco

Received: 31 July 2020

Revised: 27 September 2020

Accepted: 30 September 2020

\section{*Correspondence:}

Dr. Meryem Lemsanni,

E-mail: lemsani.meryam@ @otmail.com

Copyright: ( ) the author(s), publisher and licensee Medip Academy. This is an open-access article distributed under the terms of the Creative Commons Attribution Non-Commercial License, which permits unrestricted non-commercial use, distribution, and reproduction in any medium, provided the original work is properly cited.

\begin{abstract}
Transolecranon fracture-dislocations are rare, misdiagnosed, and challenging traumatic injuries. Consensually, they are managed surgically to restore a mobile, stable and painless elbow joint. There is a relative paucity of studies on this subject in the literature. The purpose of this case series was to establish the epidemiological profile and to describe clinical, radiological, therapeutic and outcome characteristics of these lesions. Between 2007 and 2016, fifteen patients with median age of 36 years (18-65 years) presented to us with transolecranon fracture-dislocations. They were treated surgically and followed regularly with a mean follow-up of 46 months. The cause in the majority of cases was highenergy trauma, mainly traffic accidents $(80 \%)$. Proximal ulna fractures were comminuted in 12 patients $(80 \%)$ and open in three cases $(25 \%)$. Open reduction and internal fixation with $3.5 \mathrm{~mm}$ reconstruction plates through a posterior approach was used in all cases. During follow up, one patient (6\%) had developed wound infection with skin necrosis which was successfully managed by antibiotics and controlled wound healing. Solid osseous union was confirmed for all fractures with an average of 13.5 weeks. At final follow-up, 14 patients (93\%) reported excellent outcome with a mean Broberg and Morrey score (BMS) of 86.3. Although rare, transolecranon fracture-dislocations found in patients hospitalized in a high-complexity service occurred in young men who were involved in motor vehicle accidents. These injuries can be treated successfully with reconstruction plate through a posterior approach to achieve and maintain anatomical reduction by rigid internal fixation, which is essential for promoting early rehabilitation.
\end{abstract}

Keywords: Transolecranon, Fracture-dislocation, Plate fixation, Functional outcome, BMS

\section{INTRODUCTION}

Transolecranon fracture-dislocations are uncommon injuries in which the radius and ulna shafts translate together anteriorly with anterior dislocation of the radiocapitellar joint remaining intact, in contrast to monteggia injuries. ${ }^{1-3}$ This distinction has important treatment implications. In monteggia injuries, the focus of surgical reduction is anatomic alignment of the ulnar diaphyseal fracture; whereas in trans-olecranon fracture- dislocations, the goal is stable restoration of the greater sigmoid notch. ${ }^{4,5}$

In transolecranon fracture-dislocations, disruption of osseous structures leads to elbow instability and ulnohumeral incongruity. Thereby, operative treatment is indicated to obtain an accurate anatomic reduction and a stable fixation with the aim of early functional rehabilitation. 
There is a relative paucity of studies on this subject in the literature. The purpose of this case series was to establish the epidemiological profile as well as to describe clinical, radiological, therapeutic and outcome characteristics of these complex lesions.

\section{CASE SERIES}

A retrospective case series was performed including skeletally mature patients with transolecranon fracturedislocations treated between January 2007 and December 2016 in a tertiary hospital specializing in orthopedics and traumatology which treats a significant number of emergency cases. All patients were operated by the same team of board-certified orthopedic surgeons and surgical fixation was performed with a $3.5 \mathrm{~mm}$ reconstruction plate. The parameters analyzed were age, gender, laterality, injury mechanism, fracture type, associated injuries, surgical approach, implant type and postoperative management.

At follow-up, clinical and radiographic examinations were performed by a clinical researcher who did not take part in the treatment. The clinical assessment included surgical site complications (wound dehiscence, infection), forearm rotation arc and the BMS. Standardized postoperative radiographs including anteroposterior and lateral views were obtained during the follow-up visits in order to evaluate fracture healing (time and disorders), implant loosening, and signs of degenerative arthritis. The mean duration of follow-up was 46 months (38-56 months).

Statistical analysis was conducted using statistical package for social studies (SPSS 22.0 software). Continuous variables were presented as medians with interquartile ranges or as means and standard deviations (SD). Frequencies and percentages were calculated for categorical variables.

The patients' characteristics are shown in (Table 1). There were 11 male and four female patients. The average age was 38 years old (range, 18-65 years old). The mechanisms of injury included motor vehicle accident (12 cases), falling from height (two cases), and wall collapse (one case). In nine cases $(60 \%)$ the right elbow was involved and three fractures (20\%) were open: two cases were classified as Gustilo grade I and one case as Gustilo grade II (Figure 1). Initial wound toilet, tetanus immunization and antibiotic therapy were initiated for these open injuries.

Examination of the brachial artery's pulse, radial and ulnar artery, capillary refill time, as well as neurological assessment of the radial, ulnar and median nerves were performed and revealed no complications.

The most common associated injury was cranial trauma (33\%), followed by limbs fractures (20\%), and abdominal trauma $(13 \%)$. A poly trauma was recorded in four $(26.7 \%)$ of the patients.

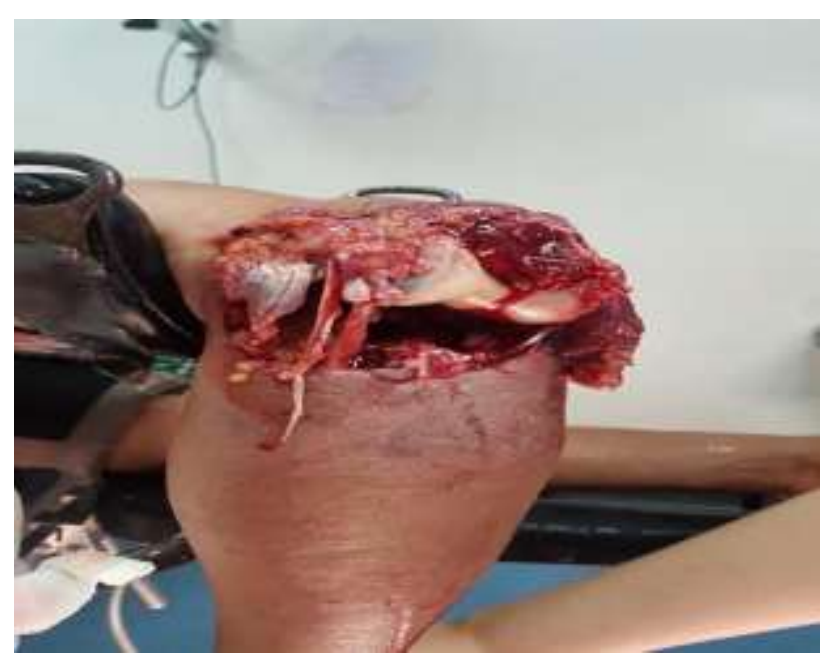

Figure 1: Clinical photograph of a Gustilo type II open transolecranon fracture-dislocation of the right elbow.

For radiographic evaluation, standard anteroposterior and lateral X-ray images of the elbow were taken. They have shown that proximal ulna fractures were comminuted in 13 patients and long oblique in two patients (Figure 2). In addition, radial head was fractured in three patients and coronoid process in one.

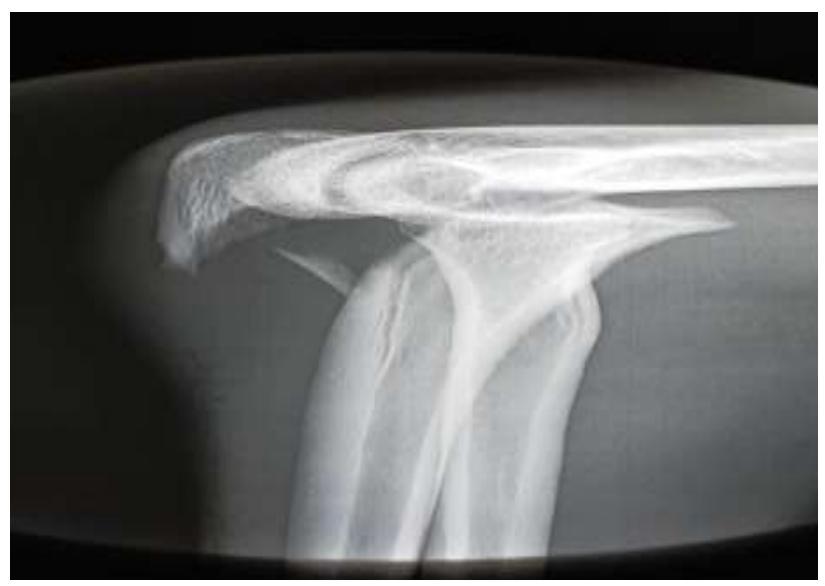

Figure 2: Lateral view X-ray of the right elbow of transolecranon fracture dislocation.

CT scans were used to obtain additional information on fracture comminution, displacement and associated injuries of the elbow in eight cases.

All patients were treated surgically at a mean of 4 days (range, 1-6 days) after the initial injury. The patients were placed in lateral decubitus position with the elbow held hyperflexed (Figure 3) and anesthetized with general $(46.7 \%)$ or regional anaesthesia $(53.3 \%)$. An arm pneumatic tourniquet was applied and inflated to 250 $\mathrm{mmHg}$ to provide a bloodless operative field. Antibiotic prophylaxis (intravenous Cefazolin $2 \mathrm{gm}$ ) was administered at the time of induction of anaesthesia in the patients with closed fractures and it was continued for 48 
hours. In patients with open fractures, 2 gm of Ceftriaxone and an aminoglycoside were administered in the emergency room. Prophylaxis was continued for 5 days.

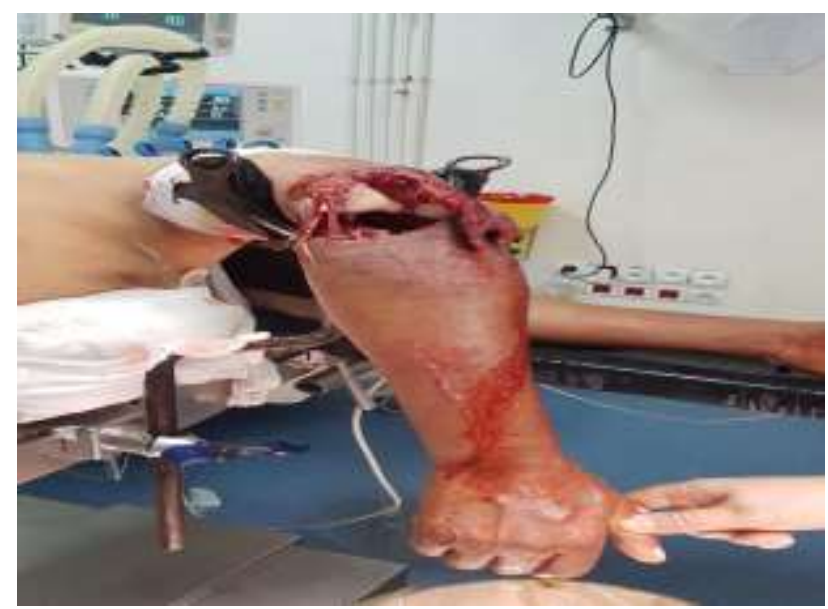

Figure 3: Patient positioned in a lateral decubitus position with the elbow held hyperflexed under tourniquet control.

Posterior approach was used in all patients. Soft tissue dissection was carefully performed to provide adequate exposure of fracture and to minimize devascularization of fragments.

Loose fragments that are intra-articular or blocking adequate reduction has been removed. Reduction was performed and was held temporarily by Kirschner wires. Fixation was undertaken using a dorsal $3.5 \mathrm{~mm}$ reconstruction plate (Figure 4). Fluoroscopic control was used to confirm anatomical reduction of the fractures, joint congruency, and the correct position of the screws (especially no penetration of the joint). Tourniquet was released before closure and meticulous haemostasis was obtained. Wounds were closed in layers over a suction drain.

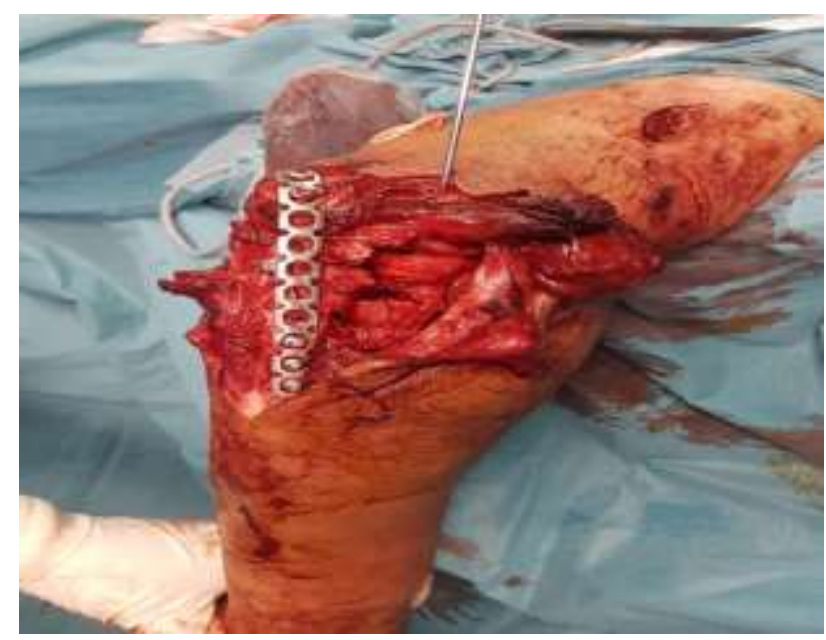

Figure 4: Intra-operative

photograph after fixation with dorsal reconstruction plate.
Postoperatively, lateral and anteroposterior X-rays were performed (Figure 5) and the elbow was immobilized (flexed $90^{\circ}$, forearm in neutral rotation) using a hinged plastic brace for three weeks for all patients. Elevation, active finger and hand motion were encouraged immediately after surgery. Supervised rehabilitationincluding active elbow flexion and extension- was started when pain and swelling had subsided, then the frequency of exercises and the range of motion were gradually increased. Isometric upper extremity muscle contraction was also encouraged.

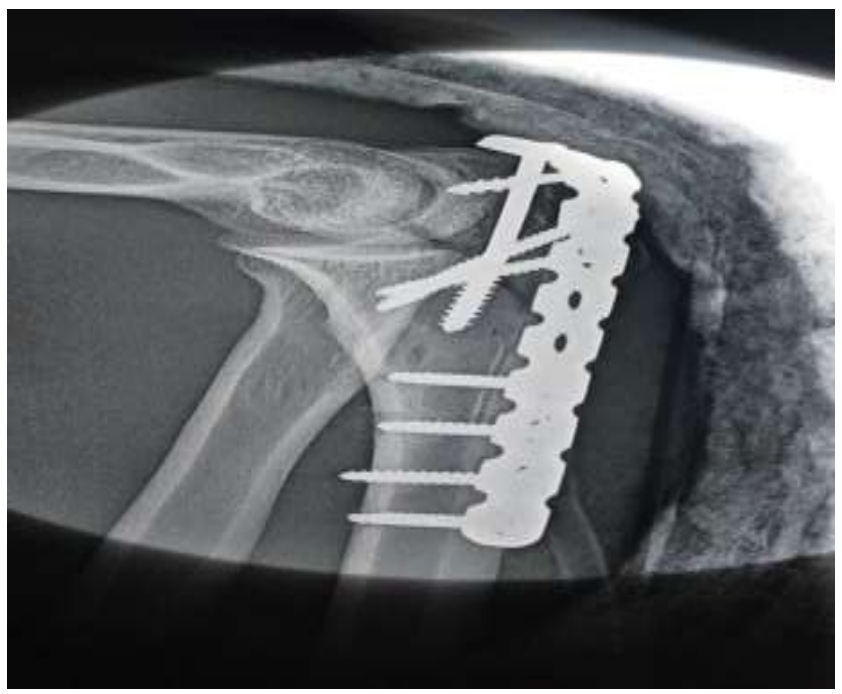

Figure 5: Post-operative lateral $X$-rays of the elbow of anatomical reduction and fixation by dorsal reconstruction plate.

All patients included in this series completed their followup. The patient, with an open Gustilo grade II fracture, suffered wound infection and skin necrosis which were managed successfully by antibiotics and controlled wound healing (Figure 6). Solid osseous union was confirmed for all fractures with an average of 13.5 weeks (range: 11-18 weeks). No evidence of subsequent displacement or hardware failure, non-union, malunion was elicited in any of the patients.

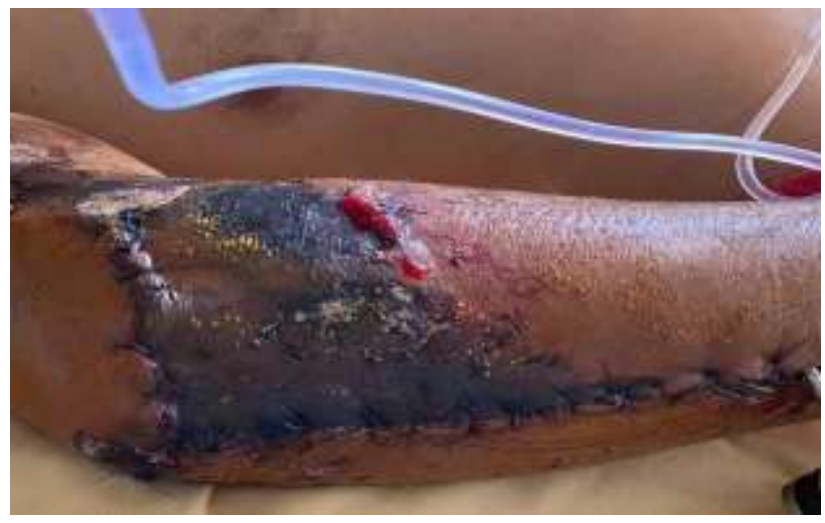

Figure 6: Wound infection and skin necrosis in a patient with an open Gustilo grade II fracture. 
Table 1: The summary of the cases.

\begin{tabular}{|c|c|c|c|c|c|c|c|c|c|c|c|}
\hline Case & $\begin{array}{l}\text { Age } \\
\text { (Year) }\end{array}$ & Gender & Side & $\begin{array}{l}\text { Injury } \\
\text { mechanism }\end{array}$ & $\begin{array}{l}\text { Fracture } \\
\text { pattern }\end{array}$ & $\begin{array}{l}\text { Skin and soft } \\
\text { tissues injuries }\end{array}$ & $\begin{array}{l}\text { Associated } \\
\text { injuries }\end{array}$ & $\begin{array}{l}\text { Follow-up } \\
\text { (months) }\end{array}$ & $\begin{array}{l}\text { Union time } \\
\text { (week) }\end{array}$ & BMS & Complications \\
\hline 1 & 24 & Male & Left & Motor cycle & $\begin{array}{l}\text { Simple, long } \\
\text { oblique }\end{array}$ & None & $\begin{array}{l}\text { Fracture of } \\
\text { radial head }\end{array}$ & 48 & 13 & 89.4 & None \\
\hline 2 & 38 & Male & Right & Motor cycle & Comminutive & None & - & 49 & 13 & 82.6 & None \\
\hline 3 & 42 & Male & Right & Auto accident & Comminutive & None & - & 44 & 15 & 89.2 & None \\
\hline 4 & 37 & Female & Left & Fall & Comminutive & Gustilo I & $\begin{array}{l}\text { Fracture of } \\
\text { coronoid } \\
\text { process }\end{array}$ & 51 & 14 & 86.5 & None \\
\hline 5 & 18 & Male & Left & Motor cycle & Comminutive & None & - & 49 & 12 & 90.2 & None \\
\hline 6 & 65 & Male & Right & Motor cycle & Comminutive & None & $\begin{array}{l}\text { Fracture of } \\
\text { radial head }\end{array}$ & 43 & 14 & 85 & Elbow stiffness \\
\hline 7 & 49 & Male & Right & Auto accident & Comminutive & None & - & 56 & 13 & 84.3 & Arthritis \\
\hline 8 & 43 & Male & Right & Fall & $\begin{array}{l}\text { Simple long } \\
\text { oblique }\end{array}$ & None & - & 38 & 11 & 86.7 & None \\
\hline 9 & 36 & Female & Right & Wall collapse & Comminutive & Gustilo II & $\begin{array}{l}\text { Fracture of } \\
\text { radial head }\end{array}$ & 46 & 18 & 81.2 & $\begin{array}{l}\text { Wound infection and } \\
\text { skin necrosis Arthritis }\end{array}$ \\
\hline 10 & 25 & Female & Right & Motor cycle & Comminutive & None & - & 44 & 14 & 88 & None \\
\hline 11 & 35 & Male & Right & Auto accident & Comminutive & Gustilo I & - & 41 & 13 & 84.5 & None \\
\hline 12 & 47 & Male & Left & Motor cycle & $\begin{array}{l}\text { Simple } \\
\text { transverse }\end{array}$ & None & - & 45 & 12 & 89.7 & None \\
\hline 13 & 22 & Male & Right & Motor cycle & Comminutive & None & - & 47 & 13 & 86.9 & None \\
\hline 14 & 39 & Male & Left & Motor cycle & Comminutive & None & $\begin{array}{l}\text { Fracture of } \\
\text { radial head }\end{array}$ & 43 & 14 & 87.3 & None \\
\hline 15 & 51 & Female & Left & Mototr cycle & Comminutive & None & - & 45 & 13 & 85.2 & None \\
\hline
\end{tabular}


The mean forearm rotation arc was $164.89 \pm 11.45$ degree and fourteen patients achieved a functional arc of motion. Stiffness of the involved elbow was observed in one elderly patient who had not undergone rehabilitation and degenerative arthritis was found in two fractures.

The mean BMS was 86.3 points (81.2-90.2) with 11 excellent cases and 4 good cases.

\section{DISCUSSION}

Transolecranon fracture-dislocations are uncommon complex injuries that combine a fracture of the olecranon with anterior dislocation of the radiocapitellar joint. ${ }^{1}$ The trauma mechanism has been reported to be an axial load to the dorsal aspect of the proximal forearm while the elbow is in a mid-flexion position. This force drives the distal humerus into the greater sigmoid notch causing a proximal ulna fracture. ${ }^{6}$ Furthermore, this direct mechanism usually results from high-energy trauma and can cause significant damage to the soft tissues. ${ }^{7}$

In epidemiological terms, we note that, in study, this type of injury predominantly affected men (73\%) and average patient age was 38 years. This is a young and economically active population which is affected by significant financial and social losses from this injury. This result is compatible with the literature, which reports greater incidence around 30 years of age and predominance in men. ${ }^{8}$

Motor vehicle accidents accounted for $80 \%$ of the total trauma mechanisms, with motorcycle accidents slightly more common than auto accidents. However, falling from height corresponded to only $13 \%$ while Fahsi et al showed in their study that this type of mechanism could account for up to $60 \%$ of cases. ${ }^{9}$

In high energy mechanisms, a complete physical exam must be performed to assess other visceral and musculoskeletal associated injuries. ${ }^{10}$ In addition, soft tissue assessment of the elbow and neurovascular examination of the injured upper extremity should be systematically carried out.

The diagnosis is made by evaluating anteroposterior and lateral X-rays of the elbow. The proximal ulna fracture can vary from a simple transverse or oblique fracture of the olecranon to complex and comminuted fracture patterns that involve the greater sigmoid notch as well as the coronoid process and the remainder of the proximal ulna. Computed tomography has utility in complex and comminuted injuries by detecting small intra-articular fragments, characterising the fracture for operative planning and identifying possible associated injuries. ${ }^{11}$ In 13 cases (87\%), proximal ulna fractures were complex and comminutive, associated with radial head (27\%) or coronoid process fractures (13\%). findings are in alignment with the results of Doornberg et al and Fahsi et al. ${ }^{4,9}$
Transolecranon fracture-dislocations are unstable injuries which almost always require surgical fixation to achieve anatomical restoration of the greater sigmoid notch and stable osteosynthesis to allow an early rehabilitation. ${ }^{3}$

Open reduction and internal fixation (ORIF) using dorsal plate through a posterior approach of the elbow is the most commonly used technique in managing this type of injuries, independent of fracture complexity. ${ }^{7}$ Plate types used include one-third tubular plates, $3.5 \mathrm{~mm}$ dynamic compression plates (DCP) and $3.5 \mathrm{~mm}$ reconstruction plates. The latter is more recommended by many authors because it offers a higher stability and a lower risk of hardware failure. ${ }^{12}$ Otherwise, tension wiring was used by some authors in simple transverse or oblique fractures but it was failed and revised to plate fixation. ${ }^{6}$

The outcomes achieved in our patient series compare favorably with previously reported studies. Mouhsine et al had similar outcome with $87.5 \%$ of excellent or good results according to BMS in a study conducted in 8 patients with a mean follow up of 37.4 months. ${ }^{8}$ In another study, Mortazavi et al reported 10 good or excellent BMS and 4 degenerative arthritis in 14 patients at 42 months followup. ${ }^{13}$

\section{CONCLUSION}

Although rare, transolecranon fracture-dislocations found in patients hospitalized in a high-complexity service occurred in young men who were involved in motor vehicle accidents. These injuries can be treated successfully with reconstruction plate through a posterior approach to achieve and maintain anatomical reduction by rigid internal fixation, which is essential for promoting early rehabilitation.

Funding: No funding sources

Conflict of interest: None declared

Ethical approval: Not required

\section{REFERENCES}

1. Biga N, Thomine JM. Trans-olecranal dislocations of the elbow. Rev Chir Orthop Reparatrice Appar Mot. 1974;60(7):557-67.

2. Wilkerson RD. Anterior elbow dislocation associated with olecranon fractures--review of the literature and case report. Iowa Orthop J. 1993;13:223-5.

3. O'Driscoll SW, Jupiter JB, Cohen MS, Ring D, McKee MD. Difficult elbow fractures: pearls and pitfalls. Instr Course Lect. 2003;52:113-34.

4. Doornberg J, Ring D, Jupiter JB. Effective treatment of fracture-dislocations of the olecranon requires a stable trochlear notch. Clin Orthop Relat Res. 2004;(429):292-300.

5. Wilppula E, Bakalim G. Fractures of the olecranon. Fractures complicated by forward dislocation of the forearm.Ann Chir Gynaecol Fenn. 1971;60(2):105-8. 
6. Ring D, Jupiter JB. Fracture-dislocation of the elbow. J Bone Joint Surg Am. 1998;80(4):566-80.

7. Capito NM, Paxton ES, Green A. Transolecranon Fracture-Dislocations. In: Tashjian R.Z, editor. The Unstable Elbow: An Evidence- Based Approach to Evaluation and Management. Utah, Springer; 2017;99-109.

8. Mouhsine E, Akiki A, Castagna A, Cikes A, Wettstein $\mathrm{M}$, Borens $\mathrm{O}$ et al. Transolecranon anterior fracture dislocation. J Shoulder Elbow Surg. 2007;16(3):352-7.

9. Fahsi M, Benameur H, El Andaloussi Y, Bennouna D, Fadili M, Nechad M. Les fractures-luxations transolécraniennes. Transolecranon fracture dislocation. Pan Afr Med J. 2015;22: 52.

10. Hu X, Xiang M, Chen H, Yang S, Tang H, Yang G. Operative treatment of anterior olecranon fracture- dislocation. Zhongguo Xiu Fu Chong Jian Wai Ke Za Zhi. 2012;26(12):1462-5.

11. Pérez-Ubeda MJ. Our experience in the treatment of trans-olecranon fracture-dislocation of the elbow. $\mathrm{J}$ Bone Joint Surg Br. 2006;88-B(I192).

12. Wyrick JD, Dailey SK, Gunzenhaeuser JM, Casstevens EC. Management of complex elbow dislocations: a mechanistic approach. J Am Acad Orthop Surg. 2015; 23(5):297-306

13. Mortazavi SMJ, Asadollahi S, Tahririan MA. Functional outcome following treatment of transolecranon fracture-dislocation of the elbow. Injury. 2006;37(3):284-8.

Cite this article as: Lemsanni M, Najeb Y, Chafik R, Madhar M, Haoury HE. Transolecranon fracturedislocations of the elbow: a case series of 15 patients. Int J Res Orthop 2020;6:1285-90. 